\title{
Cytomegalovirus colitis following azacitidine therapy
}

\author{
Rajal Khan $M D^{1}$, Pam Rudkin $\mathrm{PhC}^{2}$, Kuljit Grewal $\mathrm{MD}^{2}$, Jennifer Leonard $M D^{3}$, \\ Mowafak Hamodat $\mathrm{MD}^{4}$, Jim Hutchinson $\mathrm{MD}^{5}$, Peter Daley $\mathrm{MD}^{5}$
}

R Khan, P Rudkin, K Grewal, et al. Cytomegalovirus colitis following azacitidine therapy. Can J Infect Dis Med Microbiol 2011;22(3):e21-e23.

The present report describes the first recognized case of cytomegalovirus (CMV) colitis following azacitidine therapy. A 66-year-old woman with myelodysplastic syndrome developed CMV colitis, which responded to treatment with ganciclovir. Currently, patients receiving azacitidine do not undergo CMV testing, or receive prophylaxis or CMV-free blood products; however, this policy needs to be revised.

\section{La colite à cytomégalovirus après une thérapie à l'azacitidine}

Le présent rapport décrit le premier cas démontré de colite à cytomégalovirus (CMV) après une thérapie à l'azacitidine. Une femme de 66 ans atteinte du syndrome myélodysplasique a souffert d'une colite à CMV qui a réagi à un traitement au ganciclovir. Les patients qui prennent de l'azacitidine ne subissent pas de test de CMV et ne reçoivent pas de prophylaxie ou de produits sanguins sans CMV. Cependant, cette politique doit être révisée.

Key Words: Azacitidine; CMV; Colitis

A zacitidine (5-azacytidine, Vidaza [Celgene Corporation, USA]) is a cytidine analogue that was approved in 2004 for the treatment of all myelodysplastic syndrome (MDS) subtypes (1-5). Azacitidine has two main mechanisms of antineoplastic action: cytotoxic activity through the inhibition of nucleic acid synthesis via incorporation into DNA and RNA as an analogue of cytidine, and DNA hypomethylation, and restoration of normal growth control and differentiation of hematopoetic cells $(1,2)$.

The safety of azacitidine has been studied in phase III clinical trials (4). The adverse effects observed were mainly cytopenias; no opportunistic infections were reported $(1,2)$. The drug is not believed to cause significant immunosuppression.

We report a case of cytomegalovirus (CMV) colitis in a patient treated with azacitidine for MDS. To our knowledge, the present report is the first to describe this opportunistic infection in a patient treated with azacitidine.

\section{CASE PRESENTATION}

A 66-year-old Caucasian woman was diagnosed with the chronic myelomonocytic leukemia MDS subtype in October 2007, after presenting with pancytopenia, splenomegaly, fatigue and weight loss over a four-month period. Her medical history included spinal stenosis, degenerative disc disease and carpal tunnel syndrome. In August 2009, due to worsening cytopenias and transfusion dependence, the decision was made to begin treatment with azacitidine, starting in September 2009. The dosing schedule was $75 \mathrm{mg} / \mathrm{m}^{2}$ for seven consecutive days, every 28 days. Following monthly doses, her total white blood cell count dropped only slightly, from $2.0 \times 10^{9} / \mathrm{L}$ to $2.5 \times 10^{9} / \mathrm{L}$, to $1.5 \times 10^{9} / \mathrm{L}$ to $1.7 \times 10^{9} / \mathrm{L}$.

On January 21, 2010, after having undergone five cycles of therapy, she presented to the emergency room with fever, abdominal cramping and rectal bleeding. Her urine output was decreased. The patient's physical examination demonstrated a regular heart rate of 110 beats $/ \mathrm{min}$, a blood pressure of $100 / 50 \mathrm{mmHg}$ and a temperature of $38.4^{\circ} \mathrm{C}$. She appeared unwell. Her jugular venous pulsation was weak, and her abdomen was tender in both lower quadrants. There was no hepatosplenomegaly. Her bowel sounds were present, and there was no rebound tenderness. She also experienced mild fecal incontinence. Erythema was present in the perianal area; however, a digital rectal examination was not performed.

Her white blood cell count was $1.0 \times 10^{9} / \mathrm{L}$, with an absolute neutrophil count of $0.4 \times 10^{9} / \mathrm{L}$ and an absolute lymphocyte count of $0.5 \times 10^{9} / \mathrm{L}$. Her hemoglobin level was $84 \mathrm{~g} / \mathrm{L}$, and platelet count was $71 \times 10^{9} / \mathrm{L}$. The patient's electrolyte, urea, creatinine, lactate dehydrogenase, aspartate aminotransferase, alanine transaminase, alkaline phosphatase, amylase, calcium, albumin and magnesium levels were all within normal limits. Her total bilirubin level was elevated to $29 \mu \mathrm{mol} / \mathrm{L}$, and her inorganic phosphate level was decreased to $0.70 \mathrm{mmol} / \mathrm{L}$. The patient's chest radiograph showed mild chronic changes. A computed tomography scan of her abdomen showed "illdefined thickening of the rectal wall, with minimal stranding within the mesorectal fat and fascia which is associated with increased soft tissue density in the presacral space".

The patient was admitted to the hematology service with a diagnosis of febrile neutropenia. Blood cultures were drawn, and she was treated with intravenous antibiotics including ceftazidime, metronidazole and imipenem. The patient showed signs of very mild clinical improvement. Her blood cultures were negative after seven days.

Due to continued rectal bleeding, and abdominal and rectal pain, the patient underwent sigmoidoscopy on January 27, which showed the distal $7 \mathrm{~cm}$ to $8 \mathrm{~cm}$ of her rectal mucosa to be "markedly inflamed and ulcerated" (Figures 1A and 1B). The patient underwent a rectal biopsy, which was reported as "active inflammation with viral effects, compatible with CMV-like colitis". The CMV immunohistochemical stain was positive (Figure 1C), CMV immunoglobulin G antibody was reactive, CMV immunoglobulin $\mathrm{M}$ antibody was nonreactive, CMV shell-vial culture was negative and the CMV viral load was not available at the time of diagnosis. Based on immunohistochemical staining performed on the biopsy tissue, a diagnosis of CMV colitis was made. Intravenous antibiotics were discontinued, and therapy with intravenous ganciclovir was initiated on January 28, 2010, at a dose of $250 \mathrm{mg}$ every $12 \mathrm{~h}$.

At this point, the infectious diseases department was consulted. Azacitidine was held. Repeat sigmoidoscopy was undertaken on February 18, 2008, which showed dramatic improvement in rectal inflammation, with the only abnormality being a small area of

${ }^{1}$ Department of Internal Medicine; ${ }^{2}$ Division of Hematology; ${ }^{3}$ Division of Gastroenterology; ${ }^{4}$ Department of Pathology; ${ }^{5}$ Division of Infectious Diseases, Memorial University, St John's, Newfoundland and Labrador

Correspondence: Dr Peter Daley, Division of Infectious Diseases, Memorial University, Health Sciences Center, Room IJ421, Infection Control

Office, 300 Prince Phillip Drive, St John's, Newfoundland and Labrador A1B 3V6. Telephone 709-777-2089, e-mail pkd336@mun.ca 


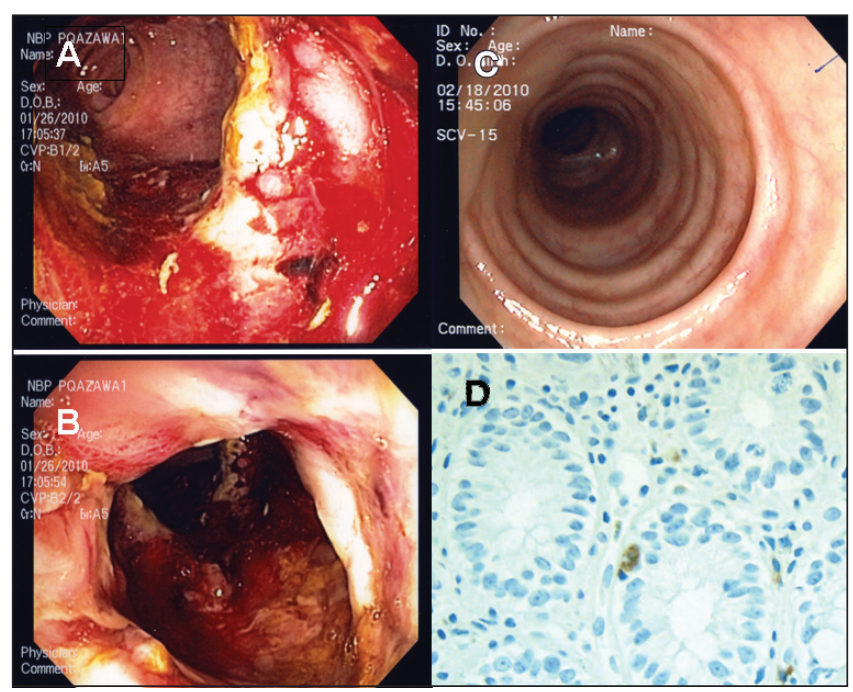

Figure 1) Sigmoidoscopy and cytomegalovirus immunostaining. Photos taken during sigmoidoscopy before (A, B) and after (C) treatment with intravenous ganciclovir. Immunostaining performed on the biopsy taken during colonoscopy shown in panel A stained positive for cytomegalovirus (D), original magnification $\times 100$

erythema in the sigmoid colon (at $25 \mathrm{~cm}$ from the rectum) (Figure 1D). Repeat biopsies of the sigmoid colon and rectum showed mild to moderate chronic inflammation with no definite morphological evidence of viral inclusions. Repeat CMV immunohistochemical stains were negative. Ganciclovir was discontinued at this point, after a total duration of three weeks, and the patient was discharged home.

The suggestion of the infectious diseases department was to monitor the serial CMV viral load for viral re-activation if the patient was to be treated further with azacitidine. No CMV suppression was recommended at the time of hospital discharge. The patient has received several more cycles of azacytidine since her discharge from the hospital. Most recent bloodwork showed a white blood cell count of $3.6 \times 10^{9} / \mathrm{L}$, with an absolute neutrophil count of $1.5 \times 10^{9} / \mathrm{L}$, hemoglobin level of $115 \mathrm{~g} / \mathrm{L}$ and a platelet count of $172 \times 10^{9} / \mathrm{L}$. She continues to do well on azacitidine treatment, with no further gastrointestinal symptoms, and is no longer dependent on red cell transfusions. Monthly viral loads have been undetectable since the time of discharge (seven months ago).

\section{DISCUSSION}

We describe a case of CMV colitis in a 66-year-old woman treated with azacitidine for MDS. To our knowledge, this is the first report of this opportunistic infection in a patient treated with this medication.

Adverse events have been reported with the use of azacitidine including nonspecific gastrointestinal symptoms (nausea, vomiting, diarrhea, constipation and anorexia), hematological events (neutropenia, anemia and thrombocytopenia), injection site events, arthralgia, cough, dyspnea, headache, dizziness, weakness and insomnia. Reported hospitalizations were from thrombocytopenia, febrile neutropenia, fever and pneumonia. However, none of these symptoms have been attributed to CMV infection (1,2).

In our patient, there was a dramatic response, both clinically and endoscopically, to treatment with intravenous ganciclovir. No formal guidelines for duration of therapy exist in this circumstance. Our decision to treat for three weeks was based on the patient's clinical and endoscopic response to ganciclovir treatment.

It is not clear, in the present case, whether there was latent CMV infection, which was reactivated by azacitidine, or whether primary infection with CMV occurred after initiation of azacitidine treatment because CMV serology was not performed before azacitidine treatment.

Azacitidine is known to activate CMV transcription promoters in vitro (6) and in vivo (7). In fact, the drug is used to facilitate gene transfer of viral vectors for cancer treatment (8), which is believed to occur through the drug's effect on DNA promoter demethylation and activation of the nuclear factor-kappa B pathway. Whether azacitidine used for treatment of MDS has any effect on reactivation of latent CMV in MDS patients is unknown.

Although severe CMV infections, including colitis (9), can affect immunocompetent hosts (10), it is generally an infection that occurs during profound immunosuppression including late-stage HIV infection (11) and following bone marrow transplant (12). Generally, conventional chemotherapies that do not cause lymphopenia or alterations in lymphocyte function are not considered to be high risk for the development of CMV disease $(13,14)$. However, isolated cases of CMV colitis have been reported after conventional chemotherapy for testicular cancer (15), non-Hodgkin's lymphoma (16), hypopharyngeal cancer (17), pancreatic carcinoma (18) and small cell lung cancer (19). CMV disease of other organ systems after conventional chemotherapy has also been reported (20). Furthermore, a recent study (21) suggested that there may be a high incidence of CMV reactivation in patients undergoing conventional chemotherapy.

The optimal approach to prevention in compromised hosts is not clear because both prophylactic and pre-emptive treatment approaches have advantages (22). There is no existent policy in Canada for CMV screening before initiation of azacitidine therapy, or for CMV chemoprophylaxis in patients known to have chronic CMV infection while being treated with azacitidine. Patients on azacitidine are not generally given CMV-free transfusions. Further study of the relationships among azacitidine, CMV promoter activation, and acute or re-activated CMV infection are needed to answer these questions. We suggest that CMV testing, monitoring and prophylaxis may be required in patients receiving azacitidine.

CONFLICTS OF INTEREST: This report received no financial support, and the authors have no conflicts of interest to declare.

\section{REFERENCES}

1. Kaminskas E, Farrell A, Abraham S, et al. Approval summary: Azacitidine for treatment of myelodysplastic syndrome subtypes. Clin Cancer Res 2005;11:3604-8.

2. Kaminskas E, Farrell AT, Wang YC, Sridhara R, Pazdur R. FDA drug approval summary: Azacitidine (5-azacytidine, Vidaza) for injectable suspension. Oncologist 2005;10:176-82.

3. Fenaux P, Mufti GJ, Hellstrom-Lindberg E, et al. Azacitidine prolongs overall survival compared with conventional care regimens in elderly patients with low bone marrow blast count acute myeloid leukemia. J Clin Oncol 2010;28:562-9.

4. Fenaux P, Mufti GJ, Hellstrom-Lindberg E, et al. Efficacy of azacitidine compared with that of conventional care regimens in the treatment of higher-risk myelodysplastic syndromes: A randomised, open-label, phase III study. Lancet Oncol 2009;10:223-32.

5. Silverman LR, Demakos EP, Peterson BL, et al. Randomized controlled trial of azacitidine in patients with the myelodysplastic syndrome: A study of the cancer and leukemia group B. J Clin Oncol 2002;20:2429-40.

6. Radhakrishnan P, Basma H, Klinkebiel D, Christman J, Cheng PW. Cell type-specific activation of the cytomegalovirus promoter by dimethylsulfoxide and 5-aza-2'-deoxycytidine. Int J Biochem Cell Biol 2008;40:1944-55.

7. Krishnan M, Park JM, Cao F, et al. Effects of epigenetic modulation on reporter gene expression: Implications for stem cell imaging. Faseb J 2006;20:106-8.

8. Gerolami R, Uch R, Jordier F, et al. Gene transfer to hepatocellular carcinoma: Transduction efficacy and transgene expression kinetics by using retroviral and lentiviral vectors. Cancer Gene Ther 2000;7:1286-92.

9. Abdulhannan P, Sugarman ID, Wood P, Puntis JW. Primary CMV colitis in an immunocompetent infant, successfully treated by gancyclovir. J Pediatr Gastroenterol Nutr 2008;47:203-5.

10. Rafailidis PI, Mourtzoukou EG, Varbobitis IC, Falagas ME. Severe cytomegalovirus infection in apparently immunocompetent patients: A systematic review. Virol J 2008;5:47. 
11. Steininger C, Puchhammer-Stockl E, Popow-Kraupp T. Cytomegalovirus disease in the era of highly active antiretroviral therapy (HAART). J Clin Virol 2006;37:1-9.

12. Yoon HS, Lee JH, Choi ES, et al. Cytomegalovirus infection in children who underwent hematopoietic stem cell transplantation at a single center: A retrospective study of the risk factors. Pediatr Transplant 2009;13:898-905.

13. Yahav D, Gafter-Gvili A, Muchtar E, et al. Antiviral prophylaxis in haematological patients: Systematic review and meta-analysis. Eur J Cancer 2009;45:3131-48.

14. Ljungman P. CMV infections after hematopoietic stem cell transplantation. Bone Marrow Transplant 2008;42(Suppl 1):S70-S72.

15. Hayashi N IK, Sano F, Makiyama K, Nakaigawa N, Kubota Y. [Case of cytomegalovirus colitis during standard chemotherapy for testicular cancer]. Nippon Hinyokika Gakkai Zasshi 2008;99:551-4.

16. Nomura K, Kamitsuji Y, Kono E, et al. Severe cytomegalovirus enterocolitis after standard chemotherapy for non-Hodgkin's lymphoma. Scand J Gastroenterol 2005;40:604-6.
17. Van den Brande J, Schrijvers D, Colpaert C, Vermorken JB. Cytomegalovirus colitis after administration of docetaxel-5fluorouracil-cisplatin chemotherapy for locally advanced hypopharyngeal cancer. Ann Oncol 1999;10:1369-72.

18. Baker JL, Gosland MP, Herrington JD, Record KE. Cytomegalovirus colitis after 5-fluorouracil and interferon-alpha therapy. Pharmacotherapy 1994;14:246-9.

19. Matthes T, Kaiser L, Weber D, Kurt AM, Dietrich PY. Cytomegalovirus colitis - a severe complication after standard chemotherapy. Acta Oncol 2002;41:704-6.

20. Chemaly RF, Torres HA, Hachem RY, et al. Cytomegalovirus pneumonia in patients with lymphoma. Cancer 2005;104:1213-20.

21. Kuo CP, Wu CL, Ho HT, Chen CG, Liu SI, Lu YT. Detection of cytomegalovirus reactivation in cancer patients receiving chemotherapy. Clin Microbiol Infect 2008;14:221-7.

22. Steininger C. Clinical relevance of cytomegalovirus infection in patients with disorders of the immune system. Clin Microbiol Infect 2007;13:953-63. 


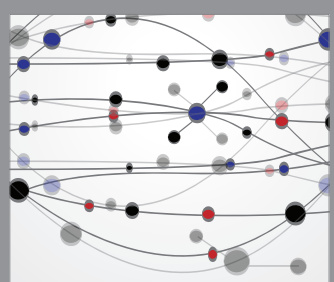

The Scientific World Journal
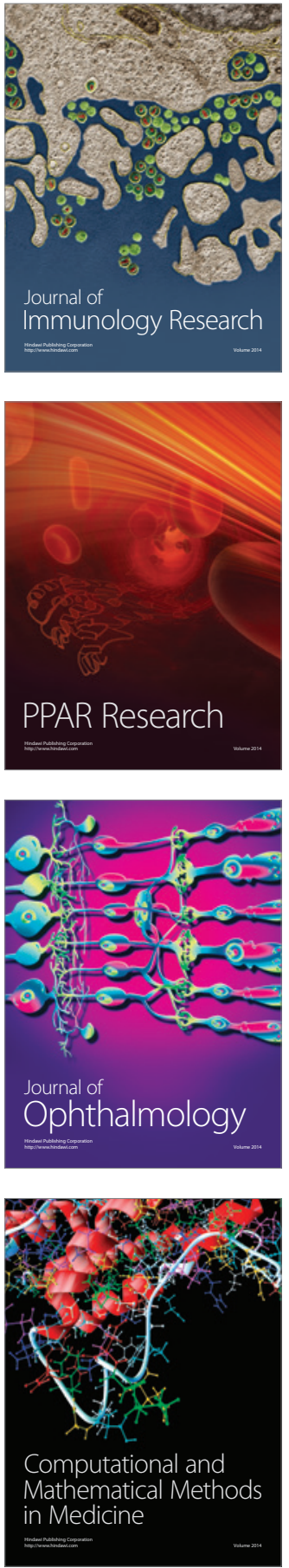

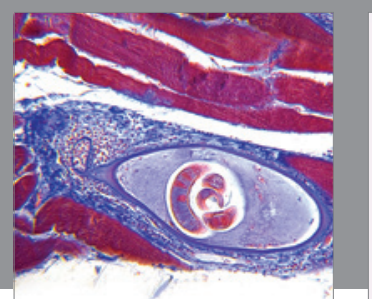

Gastroenterology Research and Practice

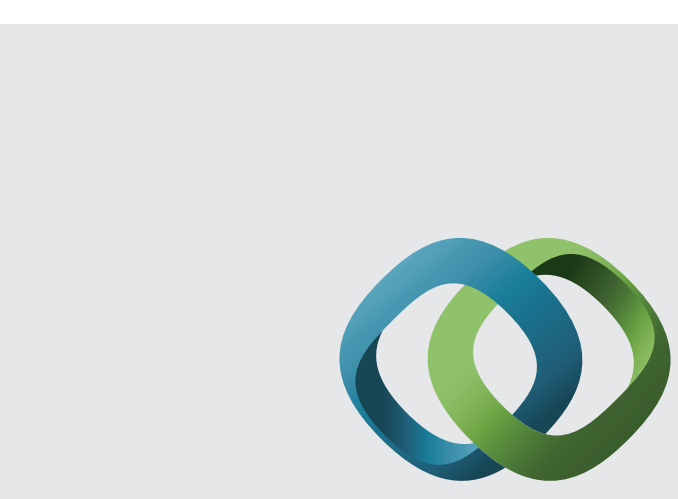

\section{Hindawi}

Submit your manuscripts at

http://www.hindawi.com
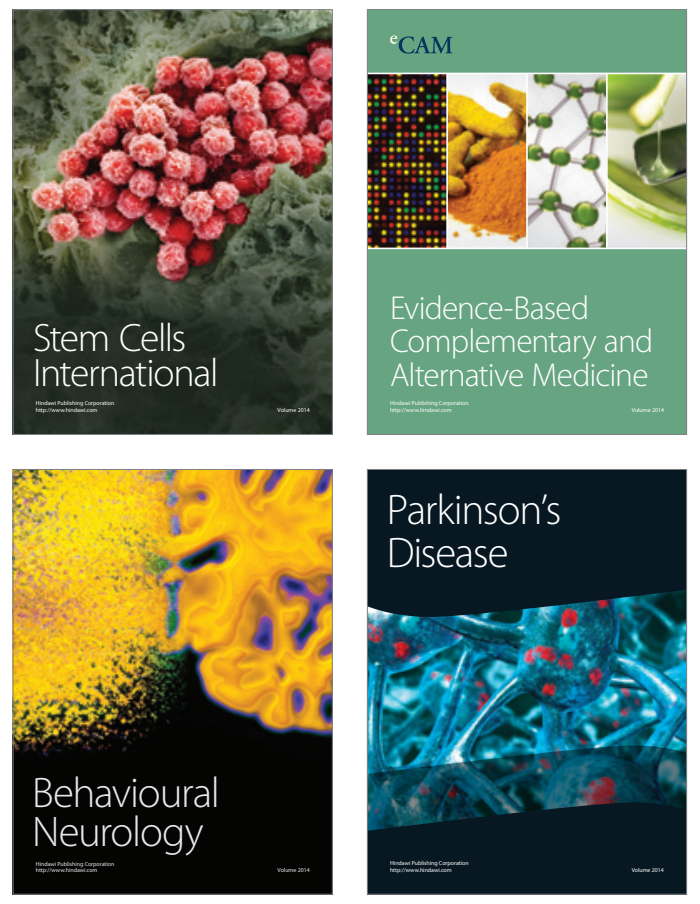
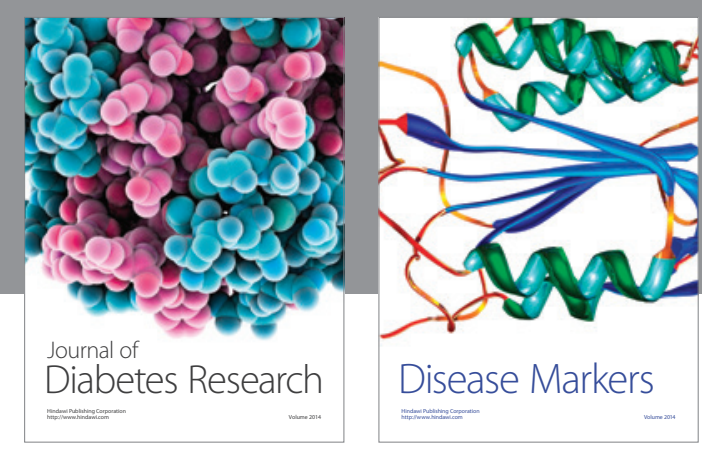

Disease Markers
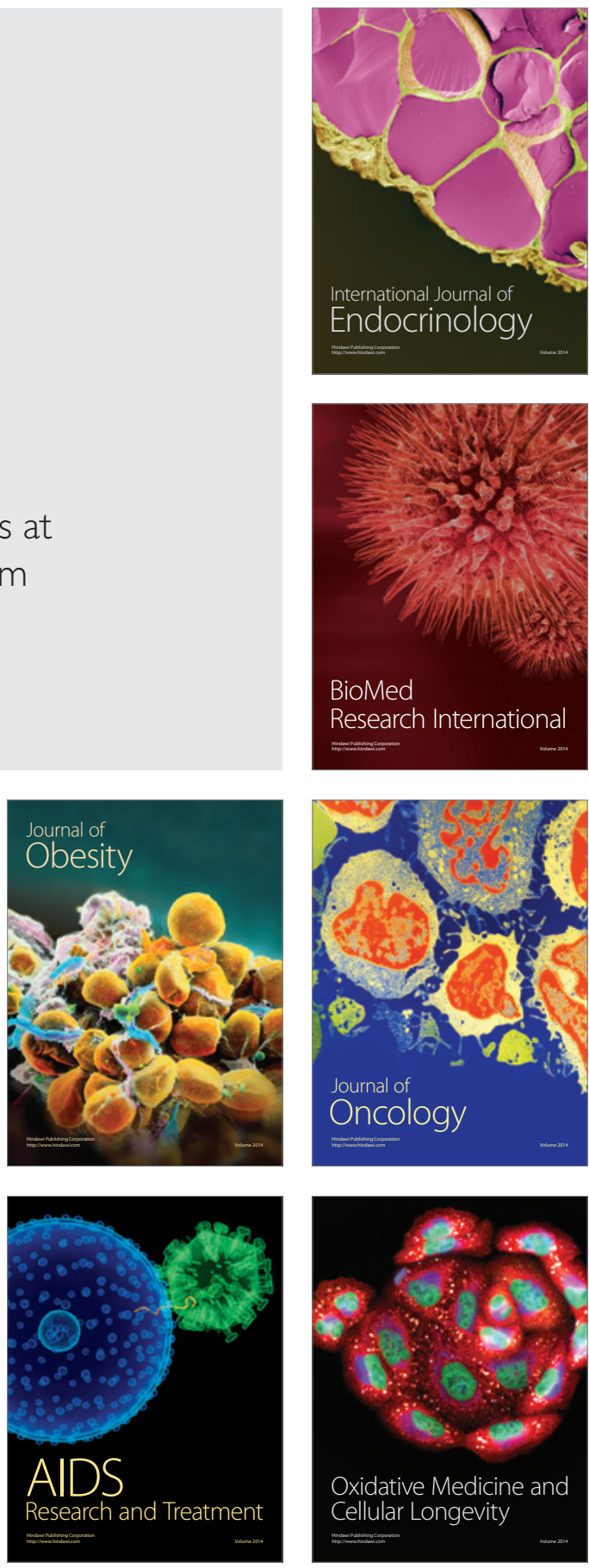